\title{
UKRAINIAN POSTER OF THE 1990's-2010's: HISTORICAL AND ART-STUDY ASPECT
}

\author{
Olena Zalevskaya \\ Department of graphic design, postgraduate student \\ Kharkiv State Academy of Design and Arts \\ 8 Mystetctv str., Kharkiv, Ukraine, 61000
}

\begin{abstract}
The article is devoted to the consideration of the formation of poster art in Ukraine during the period of Independence. It touches on the development of new trends, directions and the essence of the modern Ukrainian poster, analyzes the emotional and figurative saturation of posters of the time given. Ukrainian graphic design of that time is at the transitional stage of the evolution process from the classical-modern Soviet school to the construction of its own national design model with a vivid tone of postmodernism. It took place through the development of many factors: commercial approach is market oriented, disappearance of «dictatorship» in an art, removal from it of almost all existent limitations. Alteration assisted the professional association of designers on the territory of Soviet Union. Art of new twenty-four hours, thereby - the art of placard began to use imaginary PR technology for popularization. In the article the analytical analysis of origin of features of genre classification is done in poster graphic arts. That time development is acquired by an imaginary (advertisement) placard. Regardless of genre, it is possible to consider a show board and political placard, and social, and playbill, and other, as almost after each the commercial stands of them, or social order. The author of the article touches on a new thread in graphic design - to post-modernism. Graphic design has always borrowed images and approaches from other areas of artistic and popular culture. Visual citations, links of all kinds, mimicry of styles is an essential feature of the way of graphic design, its metamorphosis in the 20th century. The result of this was post-modernism, as the final chord of modern culture. Post-modernism calls to the correction of ideology of modernism, softens inflexibility of establishments, admits to the placard a humour, historicalquotations, ornamentalism and elements of mass culture. Also in the article an author draws a conclusion in relation to the way of development and prospects of poster graphic arts of modern Ukraine, finds out generalization of genesis of the Ukrainian poster art during 1990-2010 years.
\end{abstract}

Keywords: auteur cinema, European cinema, low-budget filmmaking, women film directors, cinema and society.

\section{Introduction}

At the turn of the century, poster art around the world was in an active phase of development. Something went back to the past and became a rarity, interruptions of the past, and something was gaining momentum. In the area of graphic design at that time, there were radical changes.

In the history of world graphic design, there are not many pages with a nationality. Incredible metamorphoses took place at the designers of the Polish school of poster, which was marked by conceptual integrity and artistic maturity, and also had an irresistible creative energy expanding the boundaries of poster art. The image, originally gravitating toward the pictorial techniques, has come to designer significance, metaphoricalness. The requirement of lapariness has led to the complication of plastic and color, the variety of texture. The emphasis on the individual style allowed the author's artistic statement, the emotional component [1].

Computer technologies, which for the first time attracted the attention of graphic designers in the early 1970's, have become the most demanded in designing and reproduction of poster products. Design-graphics that is hosted in a virtual environment is receiving more and more development. Thus, the end of the twentieth century was marked by the active introduction of information technologies in the design activity of the graphic designer. The ubiquitous computerization, which began on a global scale in the 1990's, entailed the introduction of computer graphics in the poster design, the emergence of new formal solutions and the new aesthetics of poster art. At the same time, as in previous eras, the artists are guided by the profound traditions of graphic design, combining classical experience with the latest achievements in the field of visual media and combining it with new trends in art-postmodernism[2, p. 7].

How, on the turn of the century, the development of post art in Ukraine took place... 
On August 24, 1991, the Verkhovna Rada adopted a political and legal document, known as the «Declaration of Independence of Ukraine». De jure a new state on the political map of the world appeared, de facto - the process of state building in terms of acquiring its identity and self-awareness stretched for decades. This statement concerns, as a matter of fact, socio-political and socioeconomic processes, and, equally, the artistic sphere as a whole and its graphic-designer component (and hence the poster) - in particular.

That is, the next day after the proclamation of Independence, there was nothing extraordinary in the world of Ukrainian poster graphics - till the mid-1990 it still feels the inertia of the movement acquired through restructuring processes and, at the same time, «the inertia of the orthodoxy of design culture». [3, p. 425]. These processes, in their turn, have brought radical changes in the themes, stylistic features and functionality of the Ukrainian poster, attracted polysemanticism to this kind of graphics, made it critical and revealing, and began the process of revival of national and religious culture, spiritual heritage as a whole [3, p. 424].

In particular, the tendency towards the returning of formal techniques of Ukrainian folk decorative art got further development [4, p. 75], the problems of historical memory (first of all, anti-war themes, overcoming the Stalinism and the theme of the Ukrainian national hero) [5, p. 85], the image of Vladimir Lenin on posters was finally replaced by the image of Taras Shevchenko, who, however, received the same semantic burden as the «leader of the world proletariat» [6, p. 94] (the «icon», not just «the community called the Ukrainian people», but the Ukrainian nation), and so on. The beginning of the 1990s was characterized by the returning to a poster design and aesthetics of the avant-garde traditions of the 1920 («the language of the Shattered Renaissance») and the 1950-1960 («the language of thaw»), which became a methodological tool for criticizing Stalinism and stagnation (that is, the historical periods of Ukraine of the times of the USSR, opposed to the same Shot Renewal and «rip off») through the placard [4, p. 75].

\section{Aim of research}

The aim of the work is to study the development of visual-figurative features of the Ukrainian poster of the 1990s-2010s: analysis of of trends in its development on the political and economic background.

\section{Development of the modern Ukrainian poster: genre and visual components \\ 3. 1. Processes in the poster art of the specified time}

Certain innovations of a socio-economic nature also affected the replication of posters, it was the process that was monopolized by the state for decades, which regulated not only the printing, but also the content-shaped filling of the sheets, and, besides this, also paid the work of the posters. Since the beginning of the 1990 (and sometimes also in the late 1980), the client base of the poster graphics has been expanding incredibly - the concept «private order» appeared, which, on the one hand, diversifies the material condition of the artist, expands his/her creative field, gives him/her freedom of choice, on the other - deprives guaranteed earnings and confidence in the future, puts the artist in direct dependence on the specific requirements, taste, or even simply the customer's whimsy. As a result, there was a significant outflow of posters to easel graphics, graphic design and painting [6, p. 103].

As the matter of fact, it is not necessary to speak on the turbulent dynamics of the development of Ukrainian poster art at the turn of the 1980-1990 (although the poster texts, their stylistics and figurative content have begun to change markedly since the late 1980 [6, p. 96]). This can be explained precisely by objective social and political factors - amount the other republics of the USSR, where blood began to pour out, Ukraine seemed a kind of «island of stability», since Moscow for some reason tried to prolong («conserve») stagnation at the local level [7, p. 273, p. 281-282]. Such state of affairs reflected on the Ukrainian political poster, which, largely within the formula «to criticize but not to generalize», continued to use the old slogans [6, p. 100-101], although gradually, having begun a noticeable process of deidologization [8, p. 220], lost the social and economic support from the official government, which he had from the beginning of the 1930. 
In addition, in the conditions of independent Ukraine graphics were deprived of orders and interest from the public [8, p. 229].

Therefore, although it is argued that «the poster as a form of copied graphics (and first of all, a political and social poster) has become the largest development during the periods of deep social cataclysms (revolutions, wars)» [9, p. 10], in the case of gaining independence by Ukraine, this did not happen. Probably, because the country went to «independent swimming», to a certain extent, everyday, without the above-mentioned deep (keyword) social cataclysms.

However, according to Olena Donets, the textual and informative part of the Ukrainian political posters of the 1980-1990 corresponded precisely to the crisis-transitional period, when the slogans that did not go beyond the limits of economic and industrial issues replaced appealing forms («Employees of the fuel and energy complex! Fight for the implementation of the energy program!», «Light industry workers! Accelerate the update of the product range!», «Builders and installers! Build economically and kindly on modern techniques!») to new forms appealing citizen consciousness («What did you do to accelerate scientific and technical progress?») [6, p. 95]. Gradually such a habitual propaganda component of the Soviet everyday life disappears from the poster, its content begins to be filled with philosophical contents, the world-view theses come in place of shifting slogans, visualization passes to the metaphorically abstract language of artistic means, which involves the expansion of the spectator, seen in the mind [6, p. 99].

\section{2. Gradual change of styles and directions of the Ukrainian poster}

It is difficult not to agree with the thoughts that any ideology from the poster «is washed away by the time, and only a graphic sheet in which the plastic style of the moment is preserved and the talent or inability of the creator is remained», and also that only in art poster «the game of visual and verbal and their harmonious combination occur at a high intellectual level: relaxed, laconic and operative, comprehensively revealing the talent of the artist» [6, p. 92-93]. Since art is inseparable from other spheres of life in the country and society, and the poster, by its very nature, «is the artist's response to political, social, economic, cultural or artistic events or factors» [10, p. 182], while graphic design in the whole and, by definition, is capable of «transformations under the influence of social, technical, aesthetic and other factors» [11, p. 26], then after 1991 it took some time to ensure that the same new socio-political and other factors «provoked» the development of some genres of the poster and the decay of others to happen naturally to change styles and directions, new fashion trends (trends) [4, p. 72, p. 74] have come to make the Ukrainian poster, «galloping pace», the «fast-track path of European-American art» in 1917-1991 [8, p. 228], «flipping» for some 20 years, the entire history of world art of the 20th century (Gleb Vysheslavsky argues that some modernist currents «were acquired by Ukrainian artists for several months or even weeks» [3, p. 424]), «in its own way, conversing its speeches and figurative and plastic discoveries» [12, p. 356], in the end, went into the general flow, from which it was flown away during totalitarian decades and became the part of global information structure and at the same time, formed its own specifics in the form of high positive emotionality, priority of spiritually meaningful information over pragmatics.

At the same time, the desire for national-artistic self-identification revealed obvious tendencies to weaken ties with Russian cultural space, because «globalization trends in the design culture of Ukraine for the most part of the last century were mastered under the traditional Moscow supervision and pressure» [3, p. 425]. In other words, in front of the Ukrainian poster, as well as in the Ukrainian art as a whole, there was a problem of self-determination in the interweaving of contexts - world and European, national and post-Soviet, new-state, colonial and post-colonial, modernist, postmodernist and post-postmodernist [12, p. 355].

\section{3. The essence of contemporary Ukrainian poster types' formation processes}

Due to the formation and development of democratic processes, yesterday's one-party society has sharply increased the need for election graphic propaganda products, first of all - in the political portrait poster, which, by combining imagery and propaganda functions [14, p. 91], contains images of presidential candidates, people's deputies or deputies of local councils. At the same time, the mass of such demand leveled off the actual artistic component of the political poster, led 
to the domination of a photo portrait, which some authors described as «somewhat banal» frontal «solution to the problem» of «visualization» [4, p. 72].

Along with the political posters, a poster (which, by the way, was in demand, and, of course, not in contemporary scales, even in the USSR, since 1950, became a peculiar symbol (you can even say - the background) of the quarter century of graphic design development in the conditions of independent Ukraine) [15, p. 11]) and his derivatives - billboard, banner, flyer (postcard) - as "carriers of actual artistic information» [13, p. 51]. This category also includes the cinema banner («a reseller between the film and its consumer») and theatrical posters that «have gained new breath» in connection with the emergence of alternative theaters and young directors [6, p. 98] and represent the artistically expressed effects of viewing and perceiving of a theatrical performance or film by the artist [10, p. 182].

The advertising poster was a visual embodiment of mass culture and a society of mass consumption [16, p. 305], which turned into a mass post-Soviet (including Ukrainian) society. With a certain delay (for several decades), it became acquainted with the phenomena of mass cult, which for the western consumer were already «yesterday». This is equally true in the developments in the field of graphics and poster design, where the pop art has been populated since the 1960 (associated primarily with the name of the ethnic Ukrainian Andy Warhol (Andy Warhol, Andrey Vorgola) [17, p. 6]), whose appearance was caused by «more sociology than aesthetics» [18, p. 306] and which depended on the samples created by commercial applied art, and op-art (optical art), which got accustomed exactly in the graphics and interior design. It is based on the use of optical effects: irradiation, «phenomenon of a figure and background» etc. [16, p. 310]. With the help of such advertising and graphic-poster tools, the attempts have been made to «reach» the mass consumer (including and through the advertising poster), which Volodymyr Runge called «mass» and «one-dimensional». A person who has standard, «imposed externally» needs has replaced a person with «an independent personality» and «an active life position» [16, p. 316].

In general, the poster, probably among all kinds of this graphics, is given to postmodernism, especially in the sense of intertextual and allegorical connections. The visual signs of the advert carriers reproduce elements of famous songs, details of works, color and the structure of the original source in order to create a new graphic image, which will contain a hint of the first creation. All this brings visual and plastic variety to the poster, makes it «alive», easy to perceive. The same is also true for retrievalism, which is reflected in the creation of well-known visual ideas that are used in new goals and contexts and are explained by nostalgia for the past, which in general is inherent in postmodernism, and specifically in the graphic design of an advertising poster, is intended to achieve a communicative purpose of impact on the consumer.

\section{Analysis of the status of Ukrainian posters 1990-2010}

The analysis of modern Ukrainian advertising posters shows the widespread use of Ukrainian national and ethnic symbols: the motifs of embroidery and vytynankas, rushnyks, pysankas, decorative painting (more often than not, Petrikovsky), a young girl in a national dress, a Cossack, a cosiness of the Ukrainian «hata», a red crescent, endless steppes, trident, flag, Hetman's mace, etc., these graphic symbols of Ukraine constitute a set of powerful archetypes that lie at the deep level of our consciousness, transforming into recognizable cultural codes. True, this does not quite correspond to the contemporary world trends in the development of graphic design, according to which «national characteristics are rapidly erased» [15, p. 12], there is a certain artistic unification and standardization, when the visual image is equally perceived in different parts of the globe, since the use of national and Ethnic motifs of one culture are atypical for use in another culture, since it makes it difficult or even impossible to read it at all.

An important instrument of society transformation during the first two decades of the 21st century is social poster and its subspecies (in particular, a social and environmental poster) [19, p. 72]. According to the classification proposed by Tetyana Igoshin, it is thematically divided into three blocks:

1) demonstration of the dangers and threats to human life, the struggle with social disabilities;

2) a declaration of values and moral standards;

3 ) a call for active actions [20, p. 16]. 
The place of dominant positive and optimistic themes in the Ukrainian social poster prior to the $1990 \mathrm{~s}$, in the conditions of independence have already taken: problems of health, domestic violence, alcoholism and smoking, violations of civil rights, personal safety, unemployment, AIDS, orphans, drugs, etc. The subject in comparison with the preceding periods as a whole became more acute and metaphorical $[6$, p. 96].

Andrey Andreykanich calls the social poster «the bearer of a new ideology of democracy, humanism and tolerance», which belongs to the sphere of social advertising [21, p. 125], and Olga Gladun defines it as «artistic projection, which visualizes social problems and possible approaches (searches) to their solution» [22, p. 23] and calls it «the most humanistic branch of graphic design» [22, p. 26]. In addition, the researcher draws attention to the dialectical relevance of the social poster, its constant appeal to the present and future with a certain deactivation of the past, since, say, «life has changed, and the theme of the Chernobyl disaster has fallen into the background: it is clear that the topic of grief cannot be equally acute to sound more than 20 years» [22, p. 28]. At the same time, it is noted that the identity of the national social posters, its specificity in comparison with the poster of Western origin, is seen in the fact that Ukrainian placadists, in the context of the coverage of the AIDS problem, focus not on «popularizing a healthy lifestyle (this is as if it is clear)». But «they are concerned with the moral and ethical upbringing of a new generation, tolerant attitude to HIV-infected» [13, p. 56].

Also, according to Olga Gladun, the division of the poster in «social» and «advertising», which was inherent in the 1990s, eventually evolved to «social/ecological» and «advertising/commercial». In this case, the ecological poster gradually fills its niche, often and simultaneously showing elements of both social and advertising poster [22, p. 23-24]. He started his career back in the 1980s (even the First Kyiv Biennial of the poster in 1989 was called «Ecology of Culture»), becoming not only a propaganda-informative, but also an incriminating tool [6, p. 96-97].

One of the leading tendencies of the Ukrainian graphic arts of the Independence era was the isolation of the author's (exhibition, exposition, non-stick) poster in a peculiar elite segment, the emergence of which is based on the narrowing of the market situation, and the reluctance of a part of the plotters-posters to depend on the customer's whims [6, p. 103].This kind of graphic art is defined as «single (non-circulatory) exclusive poster designer, created as an initiative to participate in competitions (exhibitions, festivals)» [20, p. 13]. In painting, which by definition is more personal than the draw schedule, the transition from «impersonal socialist neo-impressionism» to the individual technician explains the ideological paradigm change [8, p. 221]. Actually, quite a dramatic deliverance «ideological grip», held on the second and third year of Gorbachev's perestroika in the Soviet Union [3, p. 424], significantly influenced the fate of the Ukrainian poster.

Largely, the determination «copyright», nevertheless, relates to a cultural poster, which, by definition, is more aimed to the local audience. As an example, the project of the workshop of Professor Volodymyr Lesniak, Professor of the Kharkiv State Academy of Design and Arts «Born in Ukraine», can be found. This gallery poster portraits of famous natives of Ukrainian lands, according to Olga Gladun «sets new trends Ukrainian graphic design», which are, from the standpoint of social interpretation - a «revival of historical memory and national identity and self-determination» $[13, \mathrm{p} .56]$ from the professional point of view - in «double coding» of posters, which provides orientation both for specialists and for the general public [22, p. 30].

\section{Result}

Ksenia Kondratieva, an outstanding Russian designer, founder of the legendary «KAK» magazine, defining the common processes inherent in the design and design culture of the last decades noted that their «main pathos» consists of the «cultural and environmental direction», which seeks to resolve the contradictions of the type «international-national», «traditions-innovations», «specific-universal» [23, p. 15]. In the art of a modern Ukrainian poster, there is also something similar in the form of a desire for a synthesis of the global and national, where, on the one hand, there is the maximum unification, on the other hand - the transformed and modernized ethics $[13$, p. 57], the main characteristic elements of which are folklore, mentality, artifacts of authentic culture, national clothes, customs, traditions and distinctive culture [15, p. 117] (by the way, such following the national traditions of fine cultures is inherent to the Japanese poster, which is dis- 
tinguished by the minimalist simplicity of the solutions, the perfect balance of all compositional elements, the clear and unambiguous content load [16, p. 203]).

To a certain extent, this state of affairs could be regarded as an attempt by Ukrainian posters to go beyond the dominant European design in the second half of the 20th century functionalism (the so-called «international style»), which arose under the conditions of the artistic and aesthetic system of modernism as a set of diverse avant-garde artistic currents and directions, including in the design. Functionalism, as a general tendency in the world of contemporary design, manifested itself in the minimum of decor in its external form, in the imperceptibility of design, in real, and not the imaginary properties of things, taking into account the human factor, ergonomics, convenience of use as much as possible. The most active development of various artistic trends in Ukraine and Europe in the XX century finally formed the appearance of a modern font art posters: an asymmetrical composition of the text and functionalism (the minimum and importance of information, the clarity of the structure, the expression of the essence of the text message by means of the font). Posters of this type continue to be created today, being a nearly universal solution to work on font posters of advertising purposes. In addition to such functional, today there is a large number of complex and artistically or informatively rich font posters. Their presence is connected with the problems that arose at the end of the 20th century. a postmodernist trend in art, especially active since the beginning of computer use in design in the 1990s [24-26].

There was also the opinion that under the veil of the 20th century «there was a threat to the end of painting»...the mood of despair, hopelessness began to «spread among the artists» [27, p. 182]. The way out was found in the return to the art of the past. Thus, Ukrainian poster-artists together with other representatives of fine art in the conditions of the independent Ukraine, not only in advertising graphics, but also in other types of a poster, gradually move to positions of postmodernism (this trend has been observed in the national graphic design since the late 1980's [3, p. 425], which does not only implies a new perception of the theory and practice of creativity, but also calls into the question of the rational world order and the system of values created by the European civilization [16, p. 317]. Characteristic features of postmodernism are the lack of certain rules, criteria for self-expression, the artist has the right to choose any form, manner and means of creating his work, since the postmodern style does not have clear features in the artistic technique, but almost necessarily associated with irony, with an appeal to the temporarily experienced masterpieces of the past, relies on polysemy, unreal, and de-structuralism [27, p. 182-183]. In general, in the fine arts and graphic design, in particular, the typological feature of postmodernism is synthetism, through which the Belarusian researcher of postmodernism Elina Usovskaia calls it a «second hand» culture, or even compare it with socialist realism, which creates a serious foundation for cultural and artistic discussions[28, p. 17].

However, some art critics believe that the era of postmodernism has finished in the middle of the 1990s, after that «culture and art enter a new information age» and if «postmodernism redefined reality, mediated by art and artistic experience, so the up-to-date art works with mediated media reality» [12, p. 389].

In any case, in general, it can be stated that the Ukrainian poster during the 1990-2010, according to Olesya Avramenko, left «a difficult and specific external, actively enriched with new experiences» $[8$, p. 221], whose range stretched from almost complete stagnation, when «the hope that the young people, involved in the poster, would revive the prestige of this type of mass graphic art turned out to be premature» [6, p. 103], and even «the tendencies of» dissolution «of the poster in the adjacent types of fine arts such as painting, graphics, design outlined» [6, p. 105] to the rebirth associated with the general progress of society (by the way, the complaints of art critics about the crisis of the Ukrainian poster were common for the 1950s when nobody had to speak about such significant social disasters $[14$, p. 183]). Even there are the reasons to assimilate the national poster art to the French, which was characterized by a mixture of styles, signs of influence of various directions and schools, at the end of the 20th century. However, if the French graphics was resting on the achieved and practically not updating at that time [29, p. 58], the Ukrainian one was just «dialing up» [30, p. 5].

It is still in a «dynamic overclocking», and therefore has considerable prospects for reaching the level of, for example, the Polish poster, which in post-war Europe (largely, in the 1950s-1960s) was considered an unusual phenomenon, serving as a guide for other national schools of graphics 
and for which the sensuality of perception of social events, the citizenship of emotions, the breadth of themes, political sharpness, metaphor, symbolism, etc. were characteristic [31, p. 19].

\section{Conclusion}

1. From the above it is possible to draw conclusions: «The Ukrainian graphic design is in the transitional stage of the evolution process from the classical-modern Soviet school, through a market-oriented commercial approach, to the construction of its own national model of design» [8, p. 38].

Actually, the last quotation can be considered as the final summary of the genesis of Ukrainian poster art during the 1990s-2010s years, because of objective reasons it really continues to be in a peculiar dynamics of formation, which is different for different types of poster. So, let's say, a social poster can be considered as the most advanced in the artistic and commercial sense; a political one (the agitational, propagandistic), being commercially in-demand, is on an aesthetic margin; as much as possible, an advertising poster depends on the taste, the outlook of the customer, and therefore we do not say anything (with very few exceptions) about the original artistic and design findings; the culturological poster, on the contrary, wins in the artistic sense, but it is not almost circulated, having moved to the exhibition grounds almost exclusively.

2. Thus, today the modern Ukrainian poster in the artistic sense is, if not in a certain crisis, but in a state close to it. One can name it a «search for a national design model», you can name it another way, but the essence of the phenomenon will not change.

3. Such state of affairs can be explained by objective socio-political and socio-economic factors and the lack of demand for a poster in the former Soviet sense as an optimistic, zealous, multiply-edged agitation.

4. At the same time, the current historical moment opens up considerable prospects for postercreators, because the verbal information has lost the priority in the beginning of the XXI century, because of which the visual aspect of the visual language of graphic design acquires a special significance $[15$, p. 3].

5. Victor Danylenko defines the design (including graphic) of independent Ukraine in the first decade of its existence as a «direct legacy of the design of the Soviet period», which, although fitted in the context of the global design tradition of the twentieth century, but the industrially oriented design of the modernist model, nevertheless, has undergone even more emphasis on ascetic and «grayish» functionalism with outdated technologies, and therefore with the lag in passing through its historical stages. According to the scientist, «this heritage is a brake on the construction of a new design model in Ukraine» [32, p. 23].

6. Thus, summing up, one can state that the Ukrainian poster during the 1990s-2010s, as it sounds trivial, has gone a difficult way. Moreover, this way was individual for each type of a poster - political, social, advertising and cultural. Being an integral part of the Soviet era, now they are moving in parallel, but with significant differences caused, first of all, by the change in the socio-political and socio-economic paradigms of society's development. This, in turn, resulted, on the one hand, in reducing the demand for the poster as a product (and, consequently, the narrowing of the economic component of the activity of artists-posters), so it is not the most necessary product of ordinary Ukrainians. On the other hand, the deprivation of ideological shore has gradually expanded the methodological tool of poster graphics, bringing its artistic content to global trends, first of all - to postmodern, which, to a certain extent, determines the background of a modern Ukrainian poster.

\section{References}

[1] Polskaya shkola plakata: ekspansiya v "bolshoe" iskusstvo. Available at: http://hudcombinat. com/2017/07/14/польская-школа-плаката-экспансия-в-бо/

[2] Meny, V. (2010). Artistic-communicative features of modern poster: the newest concepts and tendencies of development in foreign practice. Saint Petersburg, 184.

[3] Vysheslavsky, G. (2006). Modern visual art of Ukraine in the period of post-modernism. Essays on the history of fine art of Ukraine of XX century. Book 2. Kyiv: Intertekhnologiya, 424-481.

[4] Abizov, V. A., Grishchenko, V. V. (2011). The main factors determining the development of a modern poster. Bulletin of the Kharkov State Academy of Design and Arts, 1, 71-75. 
[5] Tarasov, V. V., Shevchenko, V. Ya. (2017). The author's poster of the late 1980s - early 1990s in the plane of the historical source: the problem of analysis and interpretation. Bulletin of the Kharkiv State Academy of Design and arts, 2, 83-90.

[6] Donets, O. M. (2012). The Ukrainian printed poster of the second half of 1980 - early 1990s as a chronicle of socio-cultural changes of the period. Handwritten and book heritage of Ukraine. Kyiv, 15, 92-105.

[7] Yakubets, O. A. (2015). Volodymyr Shcherbytsky and the restructuring: some of the causes of political longevity. Spheres of Culture. Vol. X. Lublin, 273-286.

[8] Avramenko, O. (2006). Changes of the Paradigm of the Functioning of Fine Arts in Ukraine in the 1950s-2005. Essays on the History of Fine Arts of Ukraine of the XX Century. Book 2. Kyiv: Intertekhnologiya, 193-239.

[9] Shalinsky, I. P. (2017). Cultural code of the Ukrainian poster of the Revolution of dignity. Kyiv, 20.

[10] Shalinsky, I. (2015). Cross-Cultural Communication of Ukrainian Replicated Graphics in Contemporary Art of the 21st Century: Transformation of a Cultural Hero. Current Problems of Artistic Practice and Art Study Science, 7, 180-186.

[11] Gladun, O. D. (2008). Social / ecological poster as a phenomenon of graphic design. Bulletin of the Kharkov State Academy of Design and Arts, 4, 21-27.

[12] Sklyarenko, G. (2008). Ukrainian Art of the Second Half of 1980-2000: Events, Phenomena, Directions. Essays on the History of Fine Arts of Ukraine of the 20th Century. Book 2. Kyiv: Intertekhnologiya, 353-392.

[13] Gladun, O. (2009). Trends in Ukrainian visual and graphic communication: an emotional and substantive aspect. Modern problems of artistic education in Ukraine. Kyiv: Musical Ukraine, 49-58.

[14] Korolevsky, V. M. (2011) Ethnic motives in the modern Ukrainian poster. Bulletin of the Kharkov State Academy of Design and Arts, 2, 116-117.

[15] Kalashnikova, O. A. (2011). The figurative aspect of the visual language of graphic design (on the material of a poster). Kharkiv, 20.

[16] Runge, V. F. (2007). History of design, science and technology. Book. 2. Moscow: Architecture-S, 432.

[17] Ingrem, K. (2016). This is Vorgol. Lviv: Publishing House of the Old Lion, 80.

[18] Jenreens, C. (1977). The Language of Postmodern Architecture. London: Overseas Publications Interchange LTD, 85 .

[19] Bistryakova, V., Osadcha, A., Gula, E. (2016). Poster as a means of social advertising. Visnyk of Lviv University. Series “Art”, 17, 69-77.

[20] Igoshina, T. S. (2009). Graphic design of the domestic social posters (history and modern tendencies). Moscow, 26.

[21] Andreikanich, A. I. (2013). Poster: his types and genres. Ukrainian culture: past, present, ways of development: Scientific notes of the Rivne State Humanitarian University, 1 (19), 121-126.

[22] Gladun, O. (2008). Social poster: new tasks. Bulletin of the Kharkov State Academy of Design and Arts, 11, 26-31.

[23] Kondratyev, K. A. (2000). Design and ecology of culture. Moscow: MHKhPU them. Stroganov, 105.

[24] McLuhan, M. Man is an object of artistic manipulation. Culturology. Available at: http://www. countries.ru/library/era/bio.htm

[25] Fill, C., Fill, P. (2008). Encyclopedia of design. Concepts. Materials. Styles. Moscow: ACT; Astrel.

[26] Gomez-Palacio, B., Vit, A. (2009). Graphic design, referenced: a visual guide to the language,applications, and history of graphic design. Beverly Massachusetts: Rockport Publishers, 400.

[27] Dimshits, E. (2009). Ukrainian painting of the late 1950s - early 1990s. Essays on the history of fine art of Ukraine of XX century. Book 2. Kyiv: Intertekhnologiya, 150-192.

[28] Lyotard, J.-F. (1998). La Condition postmoderne: rapport sur le savoir. Available at: http://www. twirpx.com/file/155186/

[29] Danilenko, V. (2012). The design of Ukraine in the European dimension of the twentieth century. Essays on the history of Ukrainian design of the twentieth century. Kyiv: Phoenix, 6-34.

[30] Madievskaya, O. V. (2011). Reflection of the Ukrainian national heritage in diploma projects of graduates specializing in graphic design KDADM. Bulletin of the Kharkov State Academy of Design and Arts, 2, 38-42.

[31] Usovskaia, E. A. (2008). Postmodernism in the culture of the 20th century. Minsk: BSU, 63.

[32] Danilenko, V. Ya. (2010). The design of Ukraine in the world context of artistic and design culture of the twentieth century (national and globalization aspects). Lviv, 36. 